Article

\title{
Simulation Research on the Effect of Coupled Heat and Moisture Transfer on the Energy Consumption and Indoor Environment of Public Buildings
}

\author{
Shui Yu ${ }^{1, *}$, Yumeng Cui ${ }^{2, *}$, Yifei Shao ${ }^{1}$ and Fuhong Han ${ }^{1}$ \\ 1 School of Municipal and Environmental Engineering, Shenyang Jianzhu University, Shenyang 110168, \\ China; syf@stu.sjzu.edu.cn (Y.S.); Hanfuhong1995@stu.sjzu.edu.cn (F.H.) \\ 2 State Key Laboratory of Subtropical Building Science, South China University of Technology, \\ Guangzhou 510641, China \\ * Correspondence: hj_yushui@sjzu.edu.cn (S.Y.); 201710100909@mail.scut.edu.cn (Y.C.); \\ Tel.: +86-188-024-835-28 (S.Y.); +86-155-214-227-60 (Y.C.)
}

Received: 13 November 2018; Accepted: 26 December 2018; Published: 1 January 2019

\begin{abstract}
A building envelope is a multi-layer porous structure. It transfers heat and moisture to balance the indoor and outdoor temperature difference and water vapor partial pressure difference. This is a typical coupled heat and moisture migration process. When the space is filled with moist air, water or ice, it will directly affect the thermal properties of the material. With respect to moisture coming through the wall into the indoor building, it will also affect the indoor environment and the energy consumption due to the formation of latent heat. However, the moisture transfer process in the building envelopes is not taken into account in the current conventional thermal calculation and energy consumption analysis. This paper analyzes the indoor thermal and humidity environment and building energy consumption of typical cities in Harbin, Shenyang, Beijing, Shanghai, and Guangzhou. The results show that it is obvious that the coupled heat and moisture transfer in the building envelopes has an impact on the annual cooling and heating energy consumption, the total energy consumption, and the indoor thermal and humidity environment. The geographical location of buildings ranging from north to south influences the effect of coupled heat and moisture transfer on the annual energy consumption of the building, moving from positive to negative. It is suggested that the additional coefficient of the coupled thermal and moisture method can effectively correct the existing energy consumption calculation results, which do not take the consumption from the coupled heat and moisture in the building envelopes into account.
\end{abstract}

Keywords: coupled heat and moisture transfer; HAM model; energy consumption analysis; heat and humidity environment analysis

\section{Background}

Most of the materials of a building's wall are porous media [1-3]. When exposed to an outdoor dynamic thermal and humidity environment with large temperature variations, wind, and precipitation, the building wall material will undergo a heat and moisture exchange with the indoor environment due to the difference of temperature and water vapor pressure. The traditional analysis of a building's energy consumption and indoor thermal and humidity environment pays a great deal of attention to the heat transfer through the wall [4-6], but the effects of coupled heat and moisture transfer on the indoor environment and energy consumption of related buildings are often neglected [7]. In the calculation of the energy consumption and environment situation, we always consider several parts with a moisture balance on indoor air. These include moisture entering the zone through natural ventilation, moisture entering the zone through infiltration, moisture sources 
and moisture removed with Heating, Ventilation and Air Conditioning (HVAC) systems. However, moisture which is adsorbed or desorbed by materials and moisture transfer between the zone and outdoor environment is always ignored. Moreover, the traditional building thermal analysis only calculates the heat transfer process under a temperature difference and simplifies the heat transfer as the quantity increases linearly with the temperature difference, which has nothing to do with the average temperature. The result of this calculation is incomplete. With the rapid development of building heat and mass theory, researchers have been prompted to increase their concern about the impact of moisture transfer and coupled heat and mass in building envelopes due to the contradiction between China's energy saving and emission reduction policies and the people's pursuit of high-quality and high-comfort buildings [8].

The heat and moisture transfers were conducted under the difference of temperature and water vapor pressure between indoor and outdoor sides of buildings [4,5,9], and the process by which this was accomplished was coupling. The climatic characteristics of different regions in China vary and are affected by the geographical latitude, atmospheric circulation, and the underlying surface. Hence, China has become the country with the largest climate difference globally $[10,11]$. The annual outdoor temperature changes greatly and the indoor temperature is relatively stable under the control of air conditioning systems. Meanwhile, the average temperature of the building envelopes is becoming larger, and the heat transfer coefficient is affected by the average temperature significantly. Thereby, it affects the indoor temperature change and the radiation temperature of the inner wall surface to the human body [12]. In addition, the moisture absorption and release process by the building envelope is also accompanied by latent heat exchange [13]. The heat and mass transfer through the building envelope directly affects the main parameters of indoor thermal comfort, such as air temperature, air relative humidity, radiant temperature, etc. Thereby, it affects the thermal sensation for the occupants of the area of energy balance, such as their skin moisture and tactile sensation $[8,14,15]$.

Many studies have shown that a building's energy consumption and indoor comfort are inseparable; the goal is to minimize the energy consumption conditions to ensure acceptable indoor thermal comfort [13,16-18]. Especially in the severely cold and cold regions in northern China, the heat transfer and energy consumption in building envelopes account for a large proportion of a building's energy consumption, which is an area of great energy-saving potential [14]. To reduce building energy consumption only from the optimization of the system form, the improvement of the system efficiency [18], and the use of new materials but ignore the heat and moisture coupling effect on building energy consumption is not conducive to the implementation of fundamental building energy efficiency.

From the above analysis, it can be seen that the heat and moisture transfer process have an extremely important influence on the thermal performance of building envelopes, building energy consumption and the indoor environment. It is extremely important to simulate and assess buildings' energy consumption and indoor thermal environment.

\section{Methods}

This paper takes an independent small office building as a representative of public buildings, using expanded polystyrene (EPS) and wall rock wool as a typical external thermal insulation structure for insulation materials, and using the thermal energy simulation software WUFI-Plus (3.0, Fraunhofer, Munich, Germany) to calculate the indoor environmental parameters of office buildings in different climatic zones by the conduction transfer functions (CTF) algorithm, which only considers envelope heat transfer under a fixed heat transfer coefficient, and the combined heat and moisture (HAM) algorithm, which considers the coupled heat and moisture transfer of envelopes under a dynamic heat transfer coefficient. The material performance parameters introduce the dynamic thermal and physical parameters obtained from the experimental results and the commonly used rough constants. The influences of the heat and moisture coupling of building envelopes on the indoor thermal environment and energy consumption of buildings were analyzed. To study the annual energy 
consumption and indoor comfort of buildings from the perspective of the overall building structure, we take the moisture transfer of the envelope and dynamic heat transfer into consideration. The paper determines the influence of moisture transfer, moisture accumulation, and the dynamic thermal process on the calculation of building energy consumption and the evaluation of the indoor thermal environment. Additionally, the effect of the hygrothermal properties of the materials, air conditioning mode, and ventilation form on the indoor humidity environment was determined. We strived to use the envelope heat and moisture transfer more rationally in the building in order to achieve the purpose of reducing building energy consumption and improving indoor comfort.

\subsection{CTF Algorithm and HAM Algorithm}

In an energy consumption simulation calculation, we usually only consider the energy loss caused by heat transfer in building envelopes, for the simplicity of the calculation. Conduction transfer functions (CTFs) are is often used as a thermal balance algorithm. The entire surface heat flow is calculated by a conduction function. The heat gain of a space consists of heat sources in the room, air exchange in the two rooms, heat exchange from the room to the outdoor air and the heat convection of the room surface. The complicated calculation should be performed while considering the heat balance between the inside surface and the outside surface of the walls, the roof and the ground. In addition, there is a problem of thermal convection between the surfaces of different materials. This model solves the heat transfer problem of multilayer structures. It is a simplified method of calculating the heat transfer of building walls, ignoring the wall moisture, and it only considers the temperature difference as the driving force of the heat transfer. The problem of moisture transfer and moisture storage in the building envelope must be taken into account when analyzing the effect of heat and moisture transfer on the building indoor environment and the energy consumption of the building. HAM is a heat and moisture transfer finite element method. The coupled heat and moisture transfer model, by using this algorithm, can simulate the thermal and moisture migration and storage in the wall, and can also simulate the effects of moisture buffering. This calculation model takes into account the influence of moisture transfer on the hygrothermal properties of the materials. It updates the parameters of the variables, performs multiple iterations and takes into account the phase change and latent heat transfer in the calculation [5].

A closely coupled relationship between the thermal equilibrium equation and the moisture equilibrium equation can be established. In order to solve the coupled problem of the thermal transfer of the envelope, especially the coupled steam diffusion, liquid flux and heat transfer, the control equation is calculated as follows $[7,9,19]$ :

Energy conservation law:

$$
\left(\rho c+\frac{\partial H_{w}}{\partial \theta}\right) \cdot \frac{\partial \theta}{\partial t}=\nabla \cdot(\lambda \nabla \theta)+h_{v} \nabla \cdot\left(\delta_{p} \nabla\left(\varphi p_{s a t}\right)\right)
$$

Mass conservation law:

$$
\frac{d w}{d \varphi} \cdot \frac{\partial \varphi}{\partial t}=\nabla \cdot\left(D_{w} \frac{d w}{d \varphi} \nabla \Phi+\delta_{p} \nabla\left(\Phi p_{s a t}\right)\right)
$$

where $\varphi$-relative humidity; $t$-time, s; $\theta$-temperature, $\mathrm{K} ; \mathrm{c}$-specific heat, $\mathrm{J} / \mathrm{kg} \cdot \mathrm{K} ; \mathrm{w}$-humidity ratio, $\mathrm{kg} / \mathrm{m}^{3} ; p_{\text {sat }}$-saturated vapor pressure, $\mathrm{Pa} ; \lambda$-thermal conductivity, $\mathrm{W} /(\mathrm{m} \cdot \mathrm{K}) ; \mathrm{H}$-total enthalpy, $\mathrm{J} / \mathrm{m}^{3} ; D_{w}$-liquid diffusion coefficient, $\mathrm{m}^{2} / \mathrm{s} ; \delta_{p}$-vapor permeability coefficient; $\mathrm{kg} /(\mathrm{m} \cdot \mathrm{s} \cdot \mathrm{Pa})$; and $h_{v}$-latent heat of phase change, $\mathrm{J} / \mathrm{kg}$.

\subsection{Hygrothermal Properties of Building Materials}

A significant number of hygrothermal properties need to be considered when we consider the coupled moisture and heat transfer in the energy consumption simulation of buildings and make 
predictions regarding the indoor thermal and humidity environment. In architectural design, energy consumption analysis, and practical engineering, people often set the properties of the materials as constant values to be considered in the calculation. However, in the actual situation, there is a significant change in some parameters, which are affected by the average temperature and moisture content of the material. Then, there is a certain deviation between the simplified method commonly used in the thermal calculation and the actual situation. In particular, the construction is perennially exposed to seasonal changes. The temperature and moisture content of materials are in dynamic fluctuation [20,21]. In this paper, five kinds of building materials (EPS, mineral wool, concrete, adhesive mortar, and rendering plaster) which are used commonly in the domestic market were subjected to a series of hygrothermal property tests at the material level. A mathematical model of thermal conductivity with temperature and moisture content was constructed. Some physical properties needed to be converted in order to meet software setting requirements; then, the properties were put into the WUFI-Plus building materials database as inputs to participate in the calculation.

\subsubsection{Basic Properties of Materials}

In the conventional thermal calculation and energy consumption calculation, only the basic properties of materials can be involved in the calculation. Table 1 shows the basic data of the physical properties of the materials required in the CTF algorithm. The data are the median of the calculated values of the common physical condition parameters. All basic physical properties (Table 1) are obtained through experimental tests.

Table 1. Basic physical properties of materials.

\begin{tabular}{cccccc}
\hline Materials & Density & $\begin{array}{c}\text { Open } \\
\text { Porosity }\end{array}$ & $\begin{array}{c}\text { Specific } \\
\text { Heat }\end{array}$ & $\begin{array}{c}\text { Thermal } \\
\text { Conductivity }\end{array}$ & $\begin{array}{c}\text { Water Vapor Diffusion } \\
\text { Resistance }\end{array}$ \\
\cline { 2 - 6 } & $\mathbf{k g} / \mathbf{m}^{3}$ & - & $\mathbf{J} / \mathbf{k g} \cdot \mathbf{K})$ & $\mathbf{W} /(\mathbf{m} \cdot \mathbf{K})$ & - \\
\hline EPS & 19 & 0.95 & 1500 & 0.0382 & 51.95 \\
Mineral wool & 150 & 0.95 & 1030 & 0.0422 & 2.90 \\
$\begin{array}{c}\text { Concrete } \\
\text { Adhesive } \\
\text { mortar }\end{array}$ & 2211 & 0.17 & 873 & 0.452 & 51.87 \\
$\begin{array}{c}\text { Rendering } \\
\text { plaster }\end{array}$ & 1434 & 0.36 & 820 & 0.259 & 12.98 \\
\hline
\end{tabular}

The thermal conductivities of materials are tested by the heat flow meter method and the guarded-hot-plate method. The specific heat capacity of materials is obtained by a mixed method. Cup tests obtain the vapor permeability related with moisture content. Open porosity, bulk density and skeletal density are measured by vacuum saturation tests.

\subsubsection{Dynamic Hygrothermal Properties of Materials}

The dynamic hygrothermal physical properties of materials take into account the coupled heat and moisture transport effect, and the parameters are expressed as dynamic functions related to temperature and moisture content. In this paper, the dynamic hygrothermal properties of five materials were tested by thermal conductivity tests, cup tests, static gravimetric tests, capillary absorption tests, and vacuum saturation tests. Table 2 shows some dynamic hygrothermal properties of materials in the HAM algorithm. Table 3 shows some hygric properties of materials in the HAM algorithm.

The thermal conductivities of materials are tested by the heat flow meter method and guarded-hot-plate method. Repeatability errors, reproducibility errors and systematic errors caused by thermal contact resistance are analyzed. Then, we obtain accurate thermal conductivities of materials with temperature and humidity variations. A mathematical model of thermal conductivity with temperature and moisture content is constructed. The mathematical model of the thermal conductivity 
law can better express the thermal conductivity of materials with the change of material temperature and moisture content.

Cup tests obtain the vapor permeability related with moisture content. The water vapor permeability coefficient is an important moisture property of the material and it is used to describe the ability of water vapor to pass through the material. Thus, the water vapor permeability coefficient of the material has a great deal to do with the humidity of the environment.

Table 2. Some dynamic hygrothermal properties of building materials.

\begin{tabular}{cccc}
\hline Materials & $\begin{array}{c}\text { Thermal Conductivity } \\
\mathbf{W} / \mathbf{( m} \cdot \mathbf{K})\end{array}$ & $\begin{array}{c}\text { Equilibrium Moisture } \\
\text { Content } \mathbf{( k g / k g}, \mathbf{\%})\end{array}$ & $\begin{array}{c}\text { Water Vapor Permeability } \\
\text { Coefficient } \mathbf{~ k g} /(\mathbf{m} \cdot \mathbf{s} \cdot \mathbf{P a})\end{array}$ \\
\hline \multirow{2}{*}{ EPS } & $\lambda=1.06 \times 10^{-3} u+4.50 \times 10^{-4} T$ & & $3.7 \times 10^{-12}$ \\
& $-3.32 \times 10^{-5}+3.15 \times 10^{-2}$ & 0.68 & \\
Mineral wool & $\lambda=-3.92 \times 10^{-3} u+4.23 \times 10^{-4} T$ & $u=\ln \left[(100 \varphi+1)^{0.04} /(1-\varphi)^{0.07}\right]$ & $6.71 \times 10^{-11}$ \\
& $-4.92 \times 10^{-5}+3.59 \times 10^{-2}$ & $-3.28 \times 10^{-44} \exp (100 \varphi)$ & \\
Concrete & $\lambda=1.48 \times 10^{-2} u+2.20 \times 10^{-3} T$ & $u=\ln \left[(100 \varphi+1)^{0.03} /(1-\varphi)^{0.62}\right]$ & $\delta=3.77+0.005 u^{15}$ \\
& $2.16 \times 10^{-4}+4.19 \times 10^{-1}$ & $1.81 \times 10^{-43} \exp (100 \varphi)$ & \\
Adhesive mortar & $\lambda=9.6 \times 10^{-3} u+1.1 \times 10^{-3} T$ & $u=\ln \left[(100 \varphi+1)^{-0.07} /(1-\varphi)^{1.05}\right]$ & $\delta=8900-8883 u^{-6.78 \times 10^{-4}}$ \\
& $7.3 \times 10^{-5}+2.4 \times 10^{-1}$ & $6.0 \times 10^{-43} \exp (100 \varphi)$ & \\
Rendering plaster & $\lambda=3.9 \times 10^{-3} u+2.6 \times 10^{-3} T$ & $u=\ln \left[(100 \varphi+1)^{0.01} /(1-\varphi)^{0.97}\right]$ & $1.2 \times 10^{-11}$ \\
\hline
\end{tabular}

Table 3. Some hygric properties of building materials.

\begin{tabular}{ccccc}
\hline \multirow{2}{*}{ Materials } & $\begin{array}{c}\text { Water Absorption } \\
\text { Coefficient }\end{array}$ & $\begin{array}{c}\text { Capillary Saturation } \\
\text { Moisture Content }\end{array}$ & $\begin{array}{c}\text { Liquid } \\
\text { Diffusivity }\end{array}$ & $\begin{array}{c}\text { Vacuum Saturation } \\
\text { Moisture Content }\end{array}$ \\
\cline { 2 - 5 } & $\mathbf{k g} /\left(\mathbf{m}^{\mathbf{2}} \mathbf{s}^{\mathbf{0 . 5}}\right)$ & $\mathbf{k g} / \mathbf{m}^{\mathbf{3}}$ & $\mathbf{m}^{\mathbf{2}} \mathbf{s}$ & $\mathbf{~ k g / \mathbf { m } ^ { 3 }}$ \\
\hline Concrete & 0.0268 & 157 & $2.31 \times 10^{-8}$ & 175 \\
Adhesive mortar & 0.020 & 210 & $7.4 \times 10^{-9}$ & 360 \\
Rendering plaster & 0.0026 & -- & -- & 430 \\
\hline
\end{tabular}

Sorption isotherms are tested by static gravimetric tests. The equilibrium moisture content of EPS at each relative humidity can be considered as a constant. The calculation of the natural environment can be seen as an EPS moisture content of $0.6653(\mathrm{~kg} / \mathrm{kg}, \%)$, which is related to the closed-cell membrane structure of EPS. The difference between the absorption and desorption curve of rock wool is not obvious, and the capillary hysteresis phenomenon is weak. This is related to the open-cell structure of rock wool. The equilibrium absorption and desorption curves of concrete matrix materials are relatively close. The material difference error in the balanced absorption and desorption experiment is small. The sorption isotherms of rock wool and concrete matrix materials are fitted by the Feng formula.

The water absorption coefficient and capillary saturation moisture content are determined by capillary absorption tests. In addition, the liquid diffusion coefficient of the material can be estimated by the above two parameters. These properties are essential to analyze the liquid water storage and transfer process in the building envelope.

Vacuum saturation moisture content is measured by vacuum saturation tests. The property indicates the maximum moisture content achieved when all of the openings in the material are occupied by liquid water.

To the hygrothermal properties tests, the uncertainty is mainly from material errors and repeatability errors in one lab, which is confirmed by Feng [22]. And the average repeatability error and material error of related tests is listed in Table 4.

According to the Table 4, we find that the repeatability error is smaller than material error overall. The values are between 0.47 and 2.21. This illustrates that the tests are reliable. 
Table 4. The average repeatability error and material error of related tests.

\begin{tabular}{ccc}
\hline Materials & rs $_{\text {repeatability }} \%$ & rs $_{\text {material }} \%$ \\
\hline EPS & 2.00 & 2.11 \\
Mineral wool & 0.92 & 0.00 \\
Concrete & 0.47 & 19.48 \\
Adhesive mortar & 2.21 & 13.15 \\
Rendering plaster & 1.77 & 13.72 \\
\hline
\end{tabular}

\subsection{Model Construction}

This paper carries out a simulation analysis of five different climate areas. Harbin, Shenyang, Beijing, Shanghai, and Guangzhou are representative cities that face a severe cold A and B area, a severe cold $C$ area, a cold area, a hot summer and cold winter area, and a hot summer and warm winter area, respectively. Climate parameters include temperature, relative humidity, atmospheric pressure, solar radiation intensity, wind speed, wind direction, and so on.

The energy consumption is huge in public buildings with serious waste. Therefore, there is great energy saving potential. Office buildings occupy a large proportion of public buildings and are extremely representative. Thus, an independent small office building is analyzed as the object in this paper. This form of construction is in accordance with the relevant provisions of the domestic construction, which are set strictly. The length of construction of the office building is $14.1 \mathrm{~m}$, the width is $10.8 \mathrm{~m}$ and the height is $7.2 \mathrm{~m}$. The shape factor is 0.4659 , the construction area is $304.56 \mathrm{~m}$, the outside windows have two sides (length $2 \mathrm{~m}$, height $2 \mathrm{~m}$ and Length $1 \mathrm{~m}$, height $2 \mathrm{~m}$ ), and the window-to-wall ratios in east, west, north, and south directions are $0.2572,0.2572,0.3152$, and 0.2758 , respectively. Figure 1 shows the architectural appearance and building partition plan.

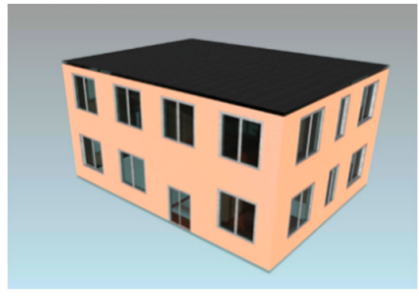

(a)

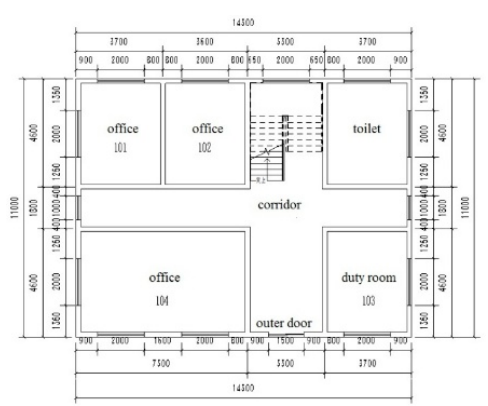

(b)

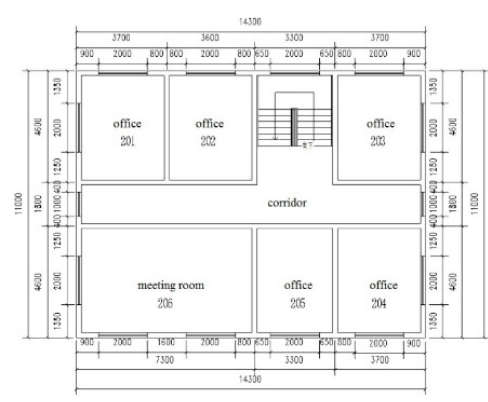

(c)

Figure 1. Outward appearance effect and floor plans of the construction. (a) The construction's outward appearance effect chart; (b) first floor plan; (c) second floor plan.

Based on the hygrothermal properties of the materials above and the limited thermal parameters in different thermal zones, the typical external thermal insulation structures were constructed. The structure of the wall is shown in Figure 2 and the wall parameters are shown in Table 5. Wall 1 has an EPS external insulation structure, and wall 2 has a rock wool insulation structure.

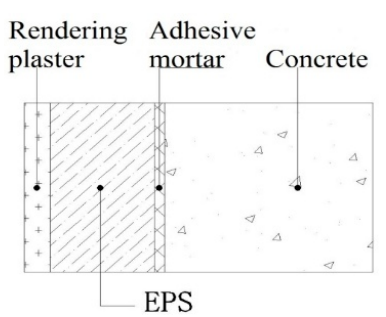

(a)

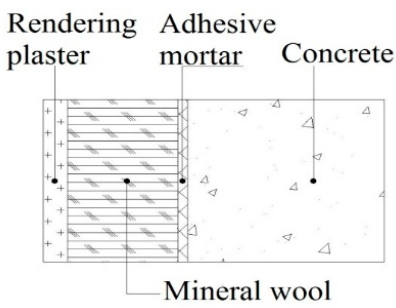

(b)

Figure 2. External insulation structure forms. (a) EPS external insulation structure form; (b) rock wool external insulation structure form. 
Table 5. Structure of building enclosure in different regions.

\begin{tabular}{|c|c|c|c|c|}
\hline \multirow{2}{*}{ Climate Zone } & \multirow{2}{*}{ Typical City } & \multirow{2}{*}{ Number } & $\begin{array}{c}\text { Heat Transfer } \\
\text { Coefficient }\end{array}$ & $\begin{array}{c}\text { Thermal } \\
\text { Resistance }\end{array}$ \\
\hline & & & {$\left[\mathrm{W} /\left(\mathrm{m}^{2} \cdot \mathrm{K}\right)\right]$} & {$\left[\mathrm{m}^{2} \cdot \mathrm{K} \cdot \mathrm{W}\right]$} \\
\hline \multirow{2}{*}{ Severe cold A and B zone } & \multirow{2}{*}{ Harbin } & Wall 1 & 0.34 & 2.79 \\
\hline & & Wall 2 & 0.34 & 2.80 \\
\hline \multirow{2}{*}{ Severe cold $\mathrm{C}$ zone } & \multirow{2}{*}{ Shenyang } & Wall 1 & 0.37 & 2.53 \\
\hline & & Wall 2 & 0.37 & 2.56 \\
\hline \multirow{2}{*}{ Cold zone } & \multirow{2}{*}{ Beijing } & Wall 1 & 0.41 & 2.26 \\
\hline & & Wall 2 & 0.40 & 2.33 \\
\hline \multirow{2}{*}{ Hot summer and cold winter zone } & \multirow{2}{*}{ Shanghai } & Wall 1 & 0.58 & 1.73 \\
\hline & & Wall 2 & 0.54 & 1.85 \\
\hline \multirow{2}{*}{ Hot summer and warm winter zone } & \multirow{2}{*}{ Guangzhou } & Wall 1 & 0.68 & 1.48 \\
\hline & & Wall 2 & 0.73 & 1.38 \\
\hline
\end{tabular}

According to GB 50189-2015, combined with the functions of the office buildings in different rooms and staff activities, the stall in-room rate, heat and humidity production, equipment and lighting power density and other parameters need to be set. Figure 3 shows the staff of the office in-room rate and the energy metabolism of staff in corridors hourly during work time.

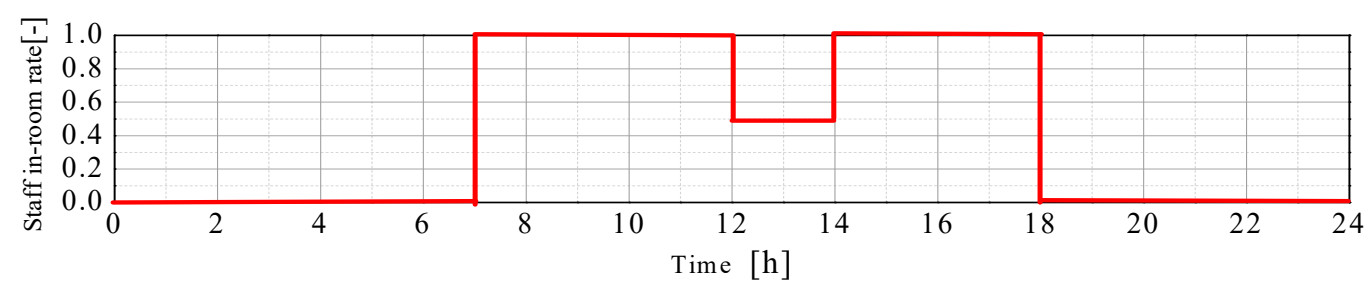

(a)

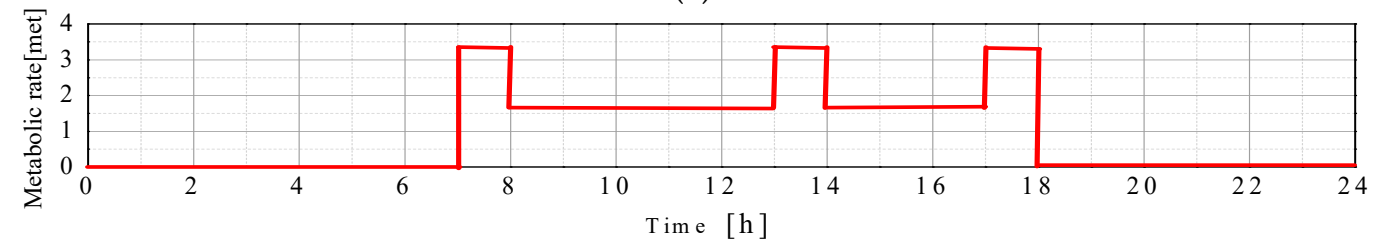

(b)

Figure 3. Office staff in-room rate and energy metabolism of staff in corridors hourly during work time. (a) Office staff in-room rate hourly in working time; (b) energy metabolism of staff in corridors hourly in working time.

According to the range of the Fanger thermal comfort model, the personnel self-regulation ability and the building energy-saving target, the indoor temperature, and the relative humidity and other indicators are defined. Figure 4 shows the temperature and the relative humidity of the controlled office, hourly during working time.

Due to the differences in climate characteristics, the air conditioning heating and cooling operation time should be set in different areas according to the actual situation. Table 6 shows the air conditioning running time in different regions throughout the year. 


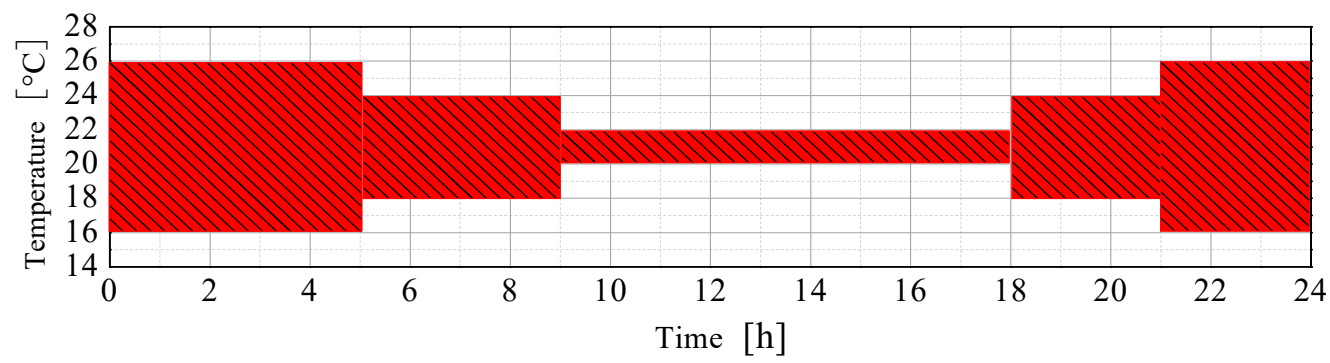

(a)

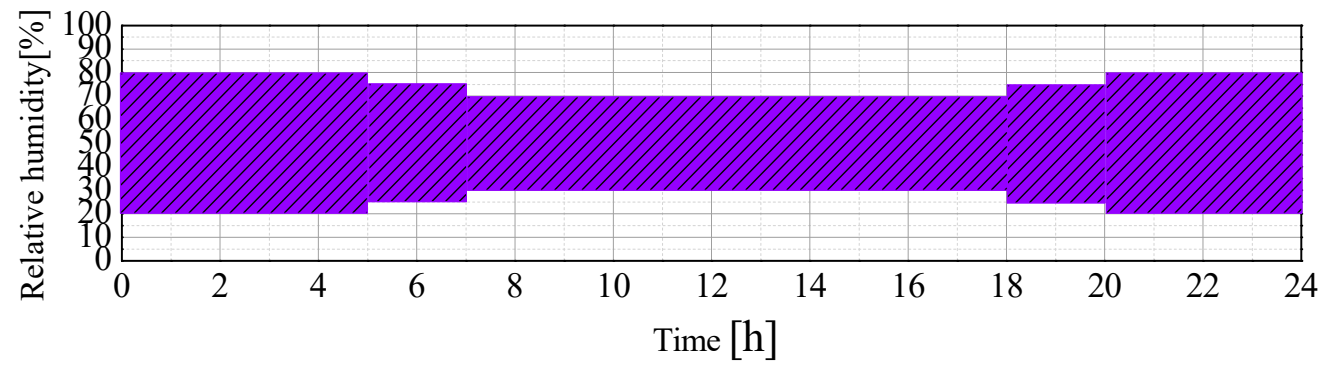

(b)

Figure 4. Temperature and relative humidity of the controlled office hourly in working time. (a) Temperature controlling method; (b) relative humidity controlling method.

Table 6. Air conditioning running time in different areas.

\begin{tabular}{ccc}
\hline Locations & $\begin{array}{c}\text { Air Conditioning } \\
\text { Running Mode }\end{array}$ & $\begin{array}{c}\text { Air Conditioning } \\
\text { Running Time }\end{array}$ \\
\hline Harbin & Heating & 20 October-20 April \\
& Cooling & 1 July-31 August \\
Shenyang & Heating & 1 November-31 March \\
& Cooling & 1 June-15 September \\
Beijing & Heating & 15 November-15 March \\
Shanghai & Cooling & 15 May-30 September \\
Guangzhou & Heating & 1 June-15 September \\
\hline
\end{tabular}

\section{Analysis of Heat and Moisture Transfer}

The climatic environment is different in different climatic zones. The extreme values and fluctuation of temperature and humidity are significantly different. The building is in an unsteady environment throughout the year. The moisture content and the average temperature change of the envelope undergo dynamic changes. In the thermal calculation, energy consumption prediction, and comfort analysis, this is directly related to the accuracy of the air conditioning system selection, the evaluation of the building energy conservation, or the envelope trade-off judgment; i.e., whether to consider the building moisture transfer, moisture storage, and dynamic heat transfer process. Then, under the premise of ensuring the indoor thermal comfort, the designer should reduce the energy consumption of the building as much as possible.

In this paper, we analyzed the effect of coupled heat and moisture transfer in building envelopes on the thermal and humidity environment and indoor human comfort using the difference results from the CTF algorithm and the HAM algorithm. In this section, all simulations only consider the natural infiltration of doors and windows without natural and mechanical ventilation. In the air conditioning system operation period, the indoor relative humidity is adjusted by the humidifier, and the indoor temperature is controlled by the air conditioning system throughout the year. 


\subsection{The Effect of Coupled Heat and Moisture Transfer on the Indoor Thermal Environment}

Indoor temperature, humidity, wind speed, and the average surface temperature are objective indices of indoor comfort. The heat exchange is achieved by convection between the indoor air temperature and humidity and the human body and radiation by the temperature difference between the room surface and the human body. The three factors are all important for the indoor thermal and humidity environment. The wind speed can be adjusted by the air conditioning system within a comfort range, and hence, it has nothing to do with the envelope heat transfer. Therefore, we analyzed three indicators-indoor temperature, humidity, and average surface temperature-in this section.

\subsubsection{The Effect of the Coupled Heat and Moisture Transfer on Indoor Temperature and Humidity}

In this section, the HAM and the CTF algorithms were used to calculate the indoor and outdoor temperature and humidity in typical urban buildings in different climatic zones. Figure 5 shows the indoor temperature and humidity status of the 101 room in five typical cities throughout the year. The green area indicates that the predicted mean vote (PMV) is between -0.5 and 0.5 , and the yellow area indicates the PMV is between -1 and 1 . When the indoor temperature and humidity points are distributed in this area, this can be regarded as a comfortable indoor environment. As the office buildings during holidays only need basic air conditioning operation to be maintained, there are a large number of state points under non-air conditioning control for uncomfortable areas.

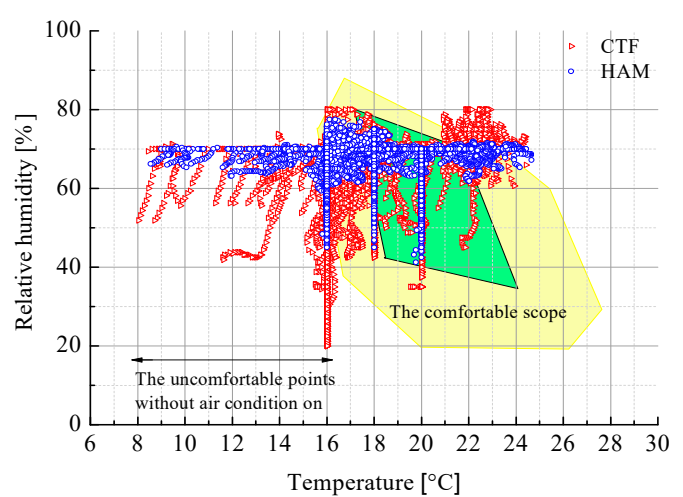

(a)

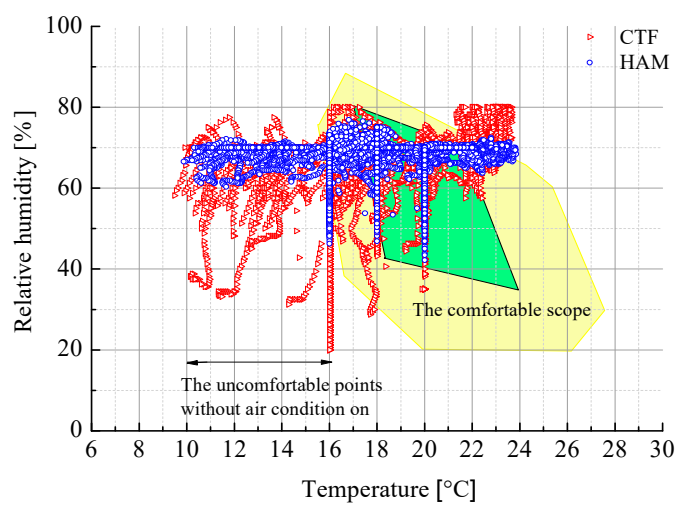

(c)

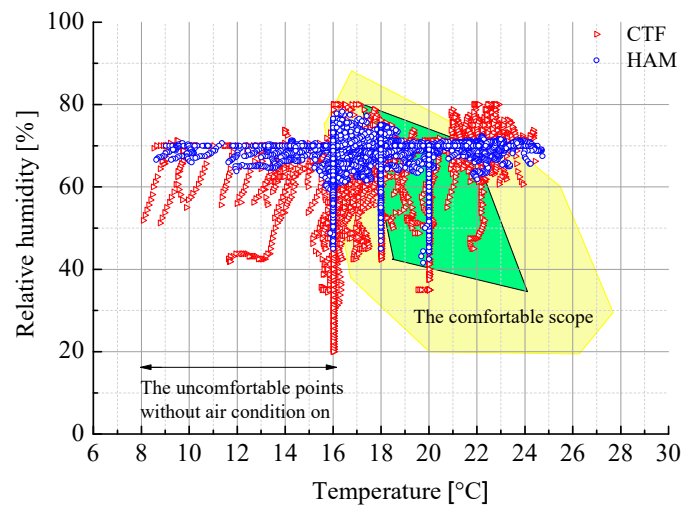

(b)

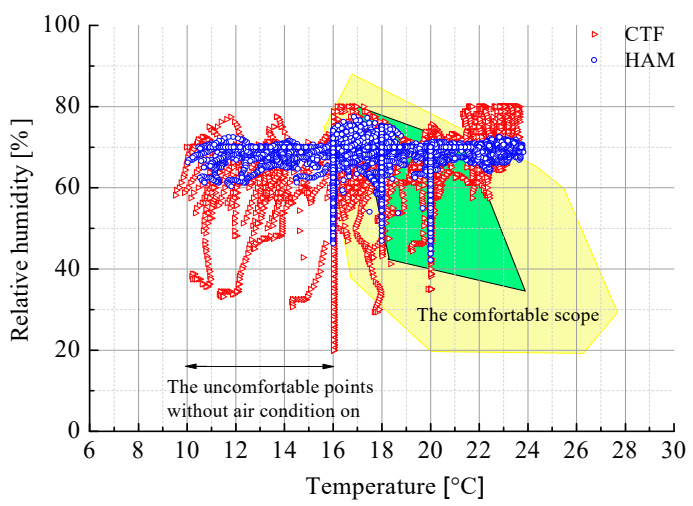

(d)

Figure 5. Cont. 


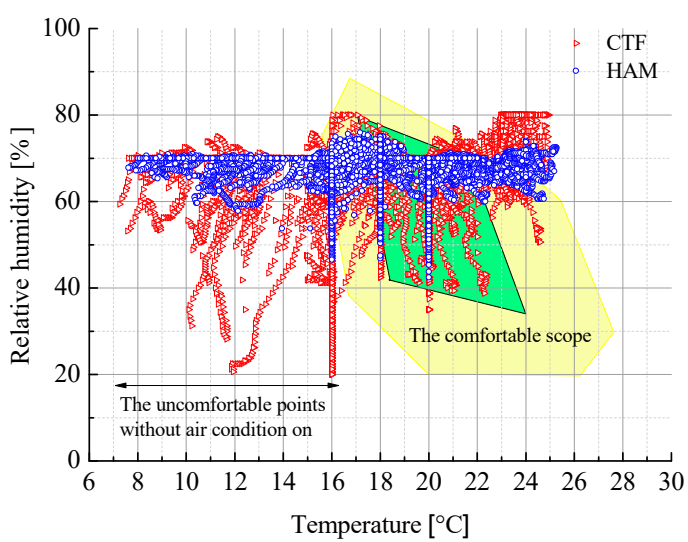

(e)

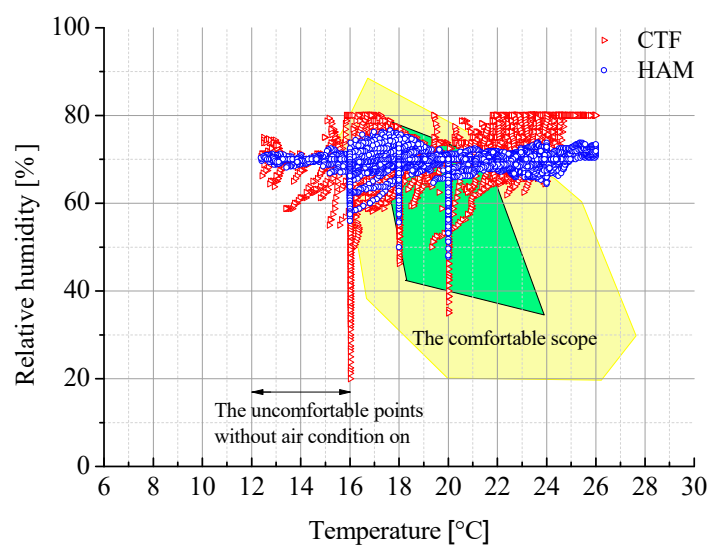

(g)

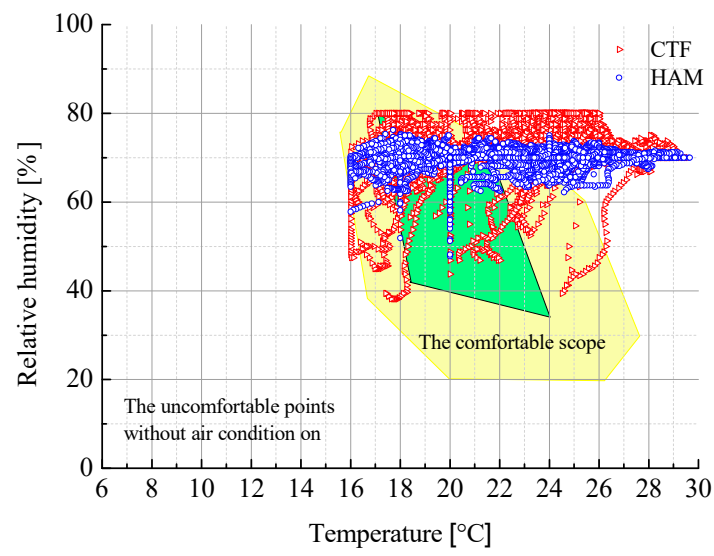

(i)

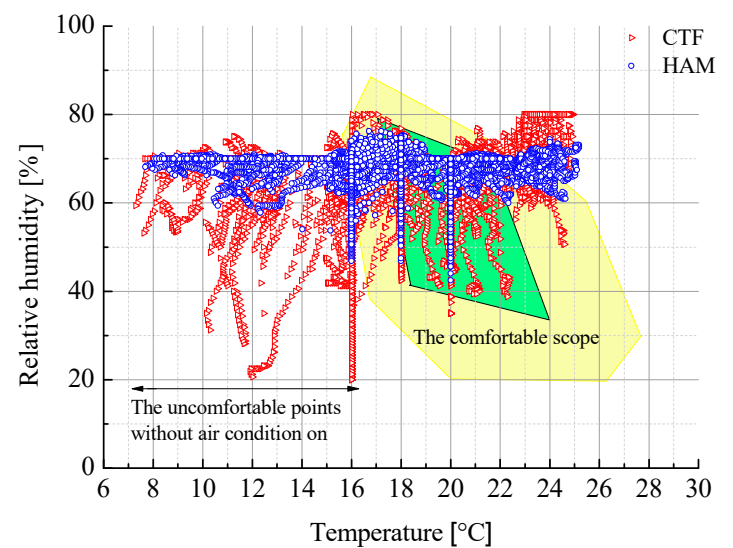

(f)

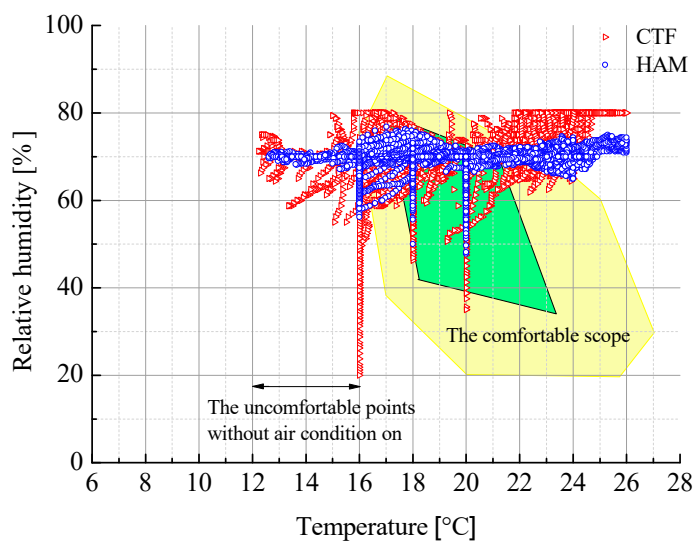

(h)

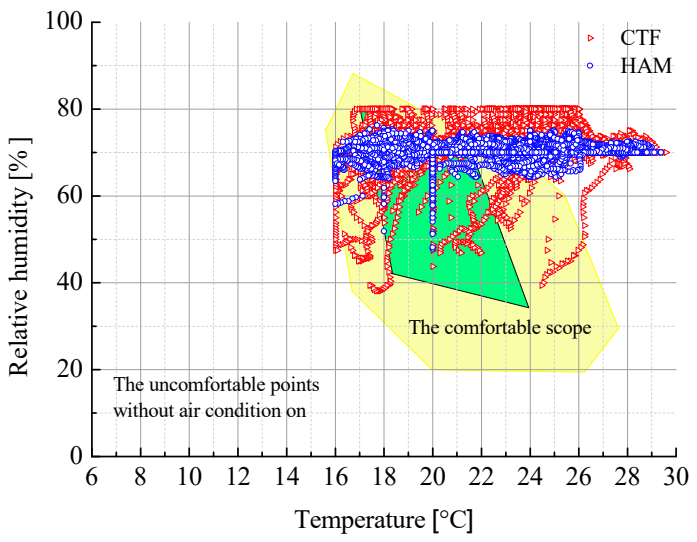

(j)

Figure 5. Interior temperature and relative humidity in the 101 room in different areas: (a) Harbin (Wall NO.1-EPS); (b) Harbin (Wall NO.2-Rock Wool); (c) Shenyang (Wall NO.1—EPS); (d) Shenyang (Wall NO.2-Rock Wool); (e) Beijing (Wall NO.1-EPS); (f) Beijing (Wall NO.1-Rock Wool); (g) Shanghai (Wall NO.1-EPS); (h) Shanghai (Wall NO.1-Rock Wool); (i) Guangzhou (Wall NO.1-EPS); (j) Guangzhou (Wall NO.1-Rock Wool).

The results show that the heat and moisture state distribution range calculated by the HAM model is narrow due to the absorption and desorption properties of the envelope. The CTF model calculates that even the distribution of the state points is narrow. The relative humidity is related to indoor staff activities when using the CTF algorithm. When staff activity is lower, moisture production is less, and hence, the relative humidity is low. When staff activity becomes greater, moisture production is 
increased, and thus, the relative humidity is high. This causes a larger fluctuation. Considering building energy efficiency, in the transition season, heat transfer by the natural environment is encouraged as much as possible without an air conditioning system. At the moment, the indoor temperature is low, and comfort is poor. When using the HAM algorithm, the moisture storage of walls is taken into account, and the use of its buffer performance can adjust relative humidity. Whether using rock wool or EPS as the insulation material of the external insulation system, the results have the same rules while using either the HAM model or the CTF model.

In short, the difference between indoor heat and the humidity environment is obvious while using the HAM model and the CTF model. Overall, the effect of coupled thermal conditions and moisture in building envelopes on the indoor air temperature and relative humidity is great. Therefore, this should be taken into account in the calculation of environmental parameters.

\subsubsection{The Effect of the Coupled Heat and Moisture Transfer on Surface Temperature}

In this section, the CTF algorithm and the HAM algorithm are used to calculate the temperature difference between the room air temperature and the surface temperature of the room. The influence of the coupled heat and moisture on the surface temperature is obtained. Figure 6 shows the room air temperature and the annual surface temperature difference of the 101 room in Harbin and Guangzhou using the HAM and the CTF algorithm.

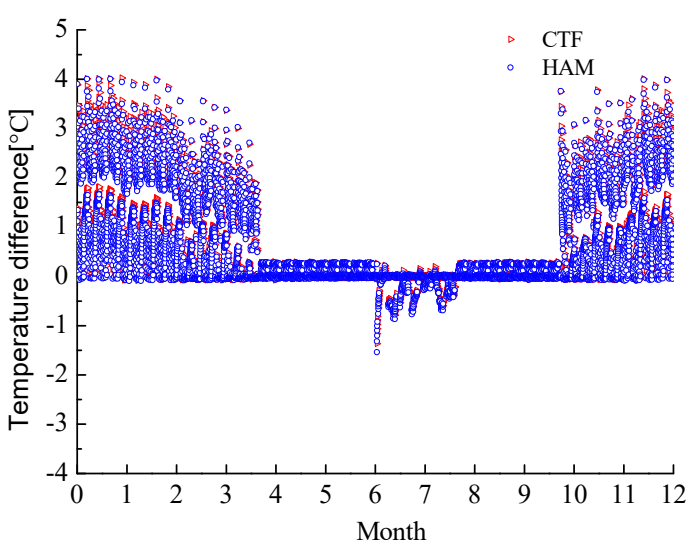

(a)

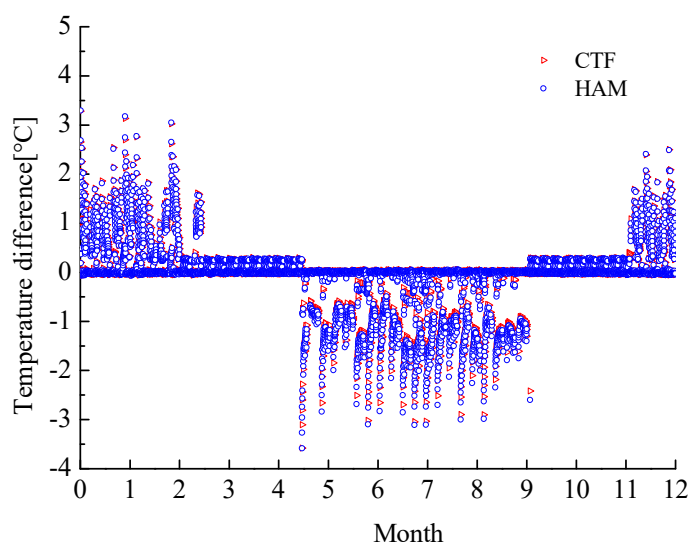

(c)

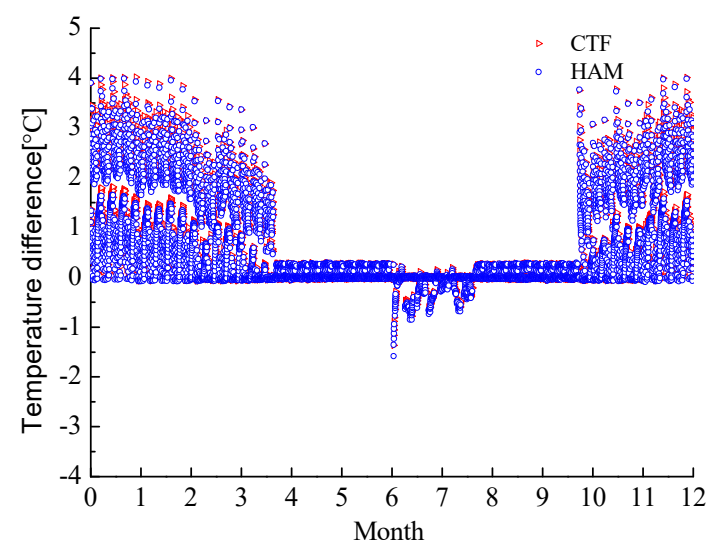

(b)

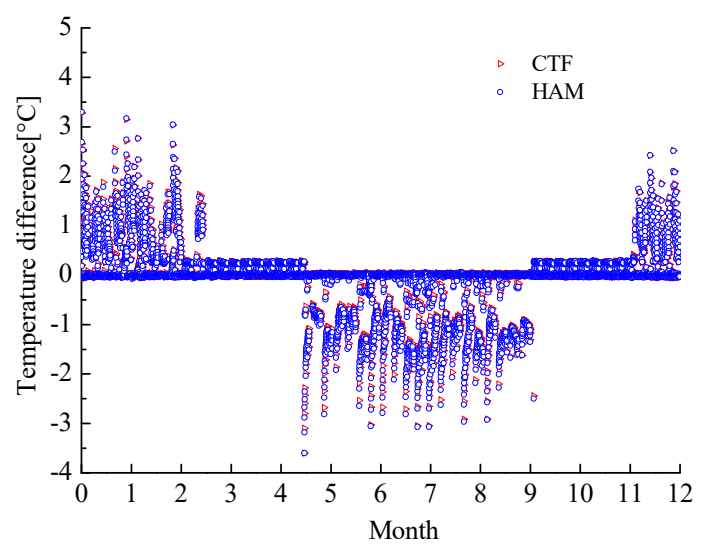

(d)

Figure 6. Air temperature and surface average temperature difference in the 101 room in different cities: (a) Harbin (Wall NO.1-EPS); (b) Harbin (Wall NO.2-Rock Wool); (c) Guangzhou (Wall NO.1-EPS); (d) Guangzhou (Wall NO.1-Rock Wool). 
The results show that the air temperature and the average surface temperature difference is not more than $5{ }^{\circ} \mathrm{C}$ in every area. The radiation heat transfer intensity of radiation is not very high, and the comfort level is high. The air temperature is slightly higher than the average radiation temperature of the room in the heating period. The calculation results of the HAM algorithm are smaller than those of the CTF algorithm. In the heating period, the average temperature difference of room temperature in Harbin, Shenyang, and Beijing are comparatively smaller, and the values are $0.15^{\circ} \mathrm{C}, 0.13^{\circ} \mathrm{C}$, and $0.1^{\circ} \mathrm{C}$, respectively, using the HAM algorithm. When the heating is on, the difference is close to zero in Shanghai and Guangzhou. The average surface temperature of the room during the cooling period is slightly higher than the air temperature. In the cooling period, the average differences of room temperature in Harbin, Shenyang, Beijing, Shanghai, and Guangzhou are comparatively smaller, and the values are $0.1{ }^{\circ} \mathrm{C}, 0.11^{\circ} \mathrm{C}, 0.15^{\circ} \mathrm{C}, 0.2^{\circ} \mathrm{C}, 0.2^{\circ} \mathrm{C}$, and $0{ }^{\circ} \mathrm{C}$, respectively, using the HAM algorithm. The effect is small due to the different insulation materials. The air conditioning is off in the transition season. The room surface temperature and air temperature are closest to the most comfortable one. This indicates that the use of natural ventilation can not only improve the indoor heat and humidity environment but also improve indoor staff comfort in the transitional season.

\subsection{The Effect of Coupled Heat and Moisture Transfer on Building Energy Consumption}

The envelope transfers heat and moisture under the driving force of temperature difference and water vapor pressure difference. The indoor and outdoor environment is different in winter, summer, and transition seasons, and thus, the direction of the heat and moisture transfer is different. Then, the effect of coupled heat and moisture in building envelopes on heating and cooling energy consumption and latent energy consumption possibly have two sides. Therefore, the total energy consumption is required for quantitative analysis. In this section, three indicators should be assessed: monthly heat and cold energy consumption, latent heat energy consumption, and the annual total energy consumption.

\subsubsection{The Effect of Coupled Heat and Moisture Transfer on Monthly Cooling and Heating Energy Consumption}

In this section, the CTF algorithm and the HAM algorithm are used to calculate the monthly energy consumption of cooling and heating in different areas. Furthermore, the influence of coupled heat and moisture on the cooling and cooling energy of the building is obtained. Figure 7 shows the monthly heating and cooling energy consumption of the 101 room in the different regions by using the CTF algorithm and the HAM algorithm.

Figure 7 shows that the heating energy consumption gradually increased, and the cooling energy consumption gradually reduced, from the north to the south. The heating energy consumption reached the maximum in January and the cooling energy consumption reached the maximum in July. The heating energy consumption in the HAM algorithm is smaller than that obtained by the CTF algorithm. When EPS is the insulation material, the maximum difference is $8.3 \%$. When the rock wool is used as the insulation material, the maximum difference is $9.37 \%$.

In terms of heat transfer, the annual temperature difference is large in a vast area of China. The average temperature of the envelope is obviously changed, and so the thermal conductivity of the material changes with it. There has been an important impact on the heat transfer coefficient of the envelope. When considering the effect of temperature change on energy consumption, the lower the temperature is, the smaller the thermal conductivity of the material will be.

The heat transfer coefficient of the wall becomes smaller. Thus, the calculation of the heating energy consumption of the room reduces with the increasing of the insulation performance of the envelope structure. The higher the temperature is, the greater the heat transfer coefficient of the wall will be. Therefore, the cooling energy consumption of the room increases with the reduced insulation performance. The effect of dynamic heat transfer is the dominant factor in the overall difference. The heating energy consumption difference is most obvious by using the two methods for the coldest 
winter in Harbin. Hence, the heating energy consumption calculated by the HAM model is smaller than the one calculated by the CTF model. However, the cooling energy consumption is larger.

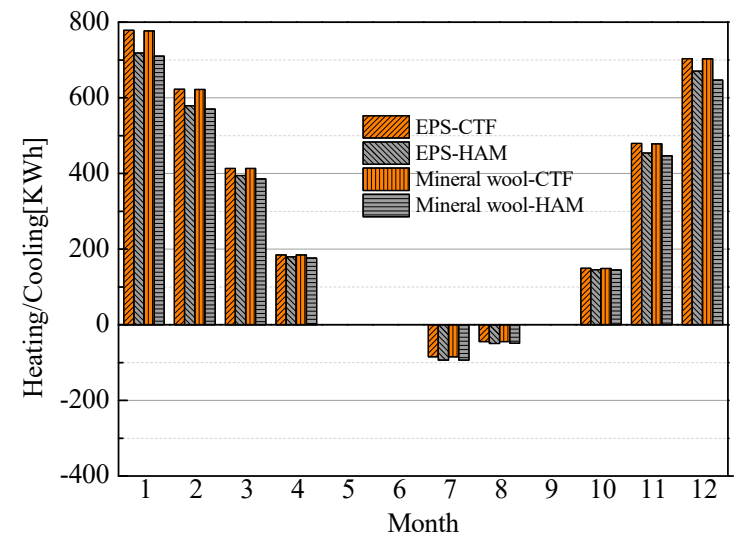

(a)

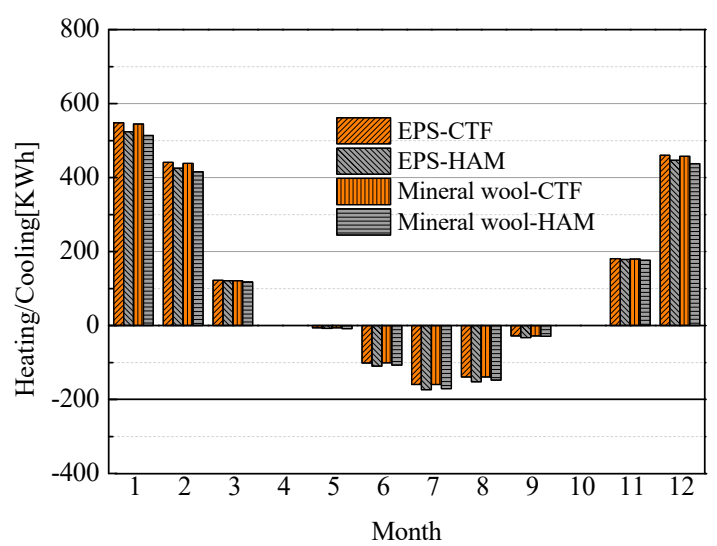

(c)

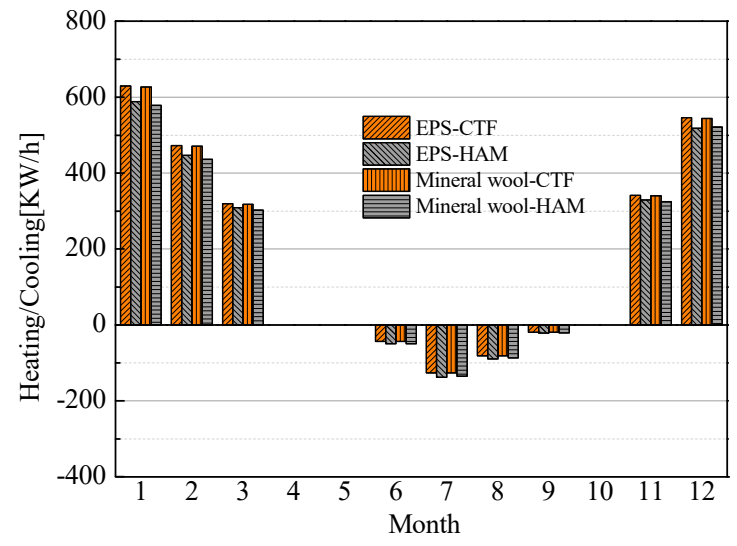

(b)

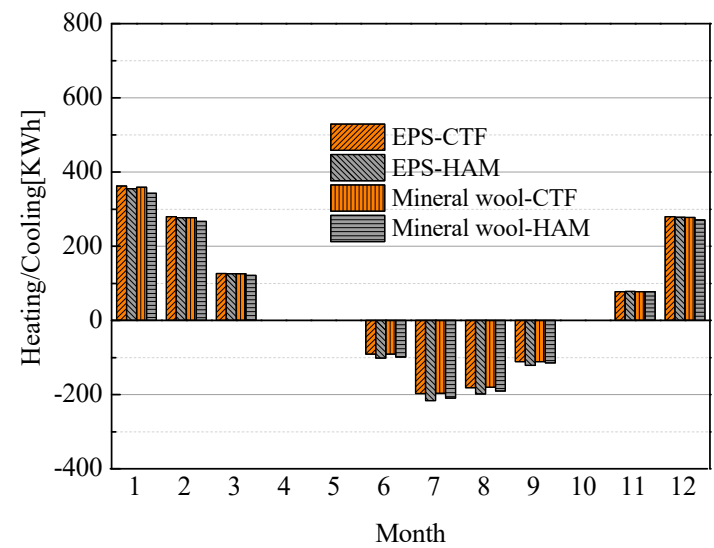

(d)

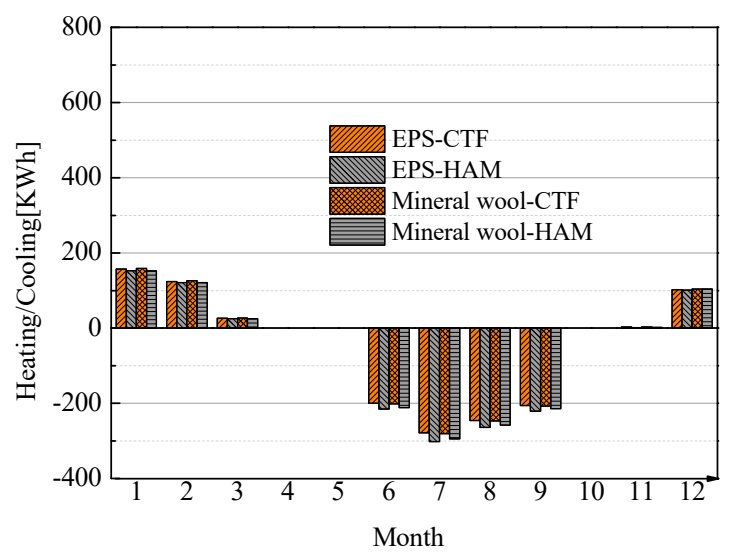

(e)

Figure 7. Heating and cooling month energy in the 101 room: (a) Harbin; (b) Shenyang; (c) Beijing; (d) Shanghai; (e) Guangzhou.

In terms of moisture, when considering the moisture transfer of the envelope, the thermal conductivity of the material increases in the moisture state. The heat transfer coefficient of the wall increases with the decreasing insulation performance. This will cause the heating energy consumption to increase. However, the impact is relatively weak. Additionally, the adsorption and desorption 
properties of the concrete wall can adjust the relative humidity, undertaking a part of the latent heat load.

\subsubsection{The Effect of Coupled Heat and Moisture Transfer on Annual Latent Heat Energy Consumption}

In this section, the CTF algorithm and the HAM algorithm are used to calculate the annual latent heat energy consumption of different buildings in different areas, and the influence of coupled heat and moisture on the annual latent heat energy of the building is analyzed. Figure 8 shows the latent heat energy consumption generated by a humidifier using the CTF and the HAM algorithm in the 101 room in different regions.

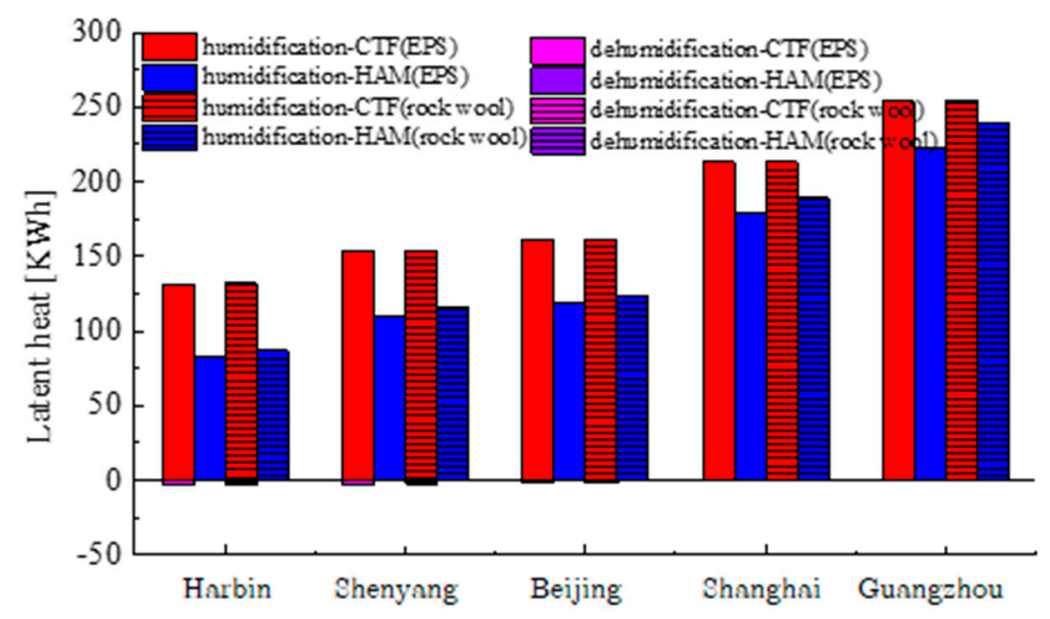

Figure 8. Annual latent heat of a humidistat in the 101 room.

It can be seen in Figure 8 that the latent heat energy consumption increases in turn from the north area to the south area. When using the HAM algorithm, the humidifier only needs to engage dehumidification all the year. However, when using the CTF algorithm, the dehumidification mode needs to be on most of the time. Furthermore, it is necessary to turn on the humidification mode for a short time. With EPS as the insulation material, the latent heat energy consumption calculated by the HAM algorithm is comparatively lower, at $58.3 \%, 39.8 \%, 36.5 \%, 18.5 \%$, and $8.8 \%$, respectively, than that by the CTF algorithm in Harbin, Shenyang, Beijing, Shanghai, and Guangzhou. The difference is obvious. For mineral wool as the insulation material, the latent heat energy consumption calculated by the HAM algorithm is comparatively lower, at $51.8 \%, 33.7 \%, 30.4 \%, 12.8 \%$, and $4.7 \%$, respectively, than that by the CTF algorithm in Harbin, Shenyang, Beijing, Shanghai, and Guangzhou. The difference was about $6 \%$ lower than those of the EPS insulation system. This is the reason that the water vapor permeability coefficient of EPS is smaller than that of mineral wool. Water vapor can pass easily through the wall into the room. Meanwhile, indoor moisture is also easier to discharge through the wall. The system can reduce the latent heat load of the room more effectively throughout the year. It is pointed out that the effect of the absorption and desorption capacity of the envelope on the relative humidity fluctuation is extremely significant. The latent heat energy obtained by the HAM calculation method is relatively small compared to the conventional algorithm.

\subsubsection{The Effect of Coupled Heat and Moisture Transfer on the Total Annual Heat} Energy Consumption

In this section, the effects of coupled heat and moisture on the total energy consumption of the two insulation systems are compared and analyzed. Figure 9 shows the comparison of the energy consumption of various parts of office buildings using EPS and rock wool insulation in different representative cities using the CTF model and the HAM model. 


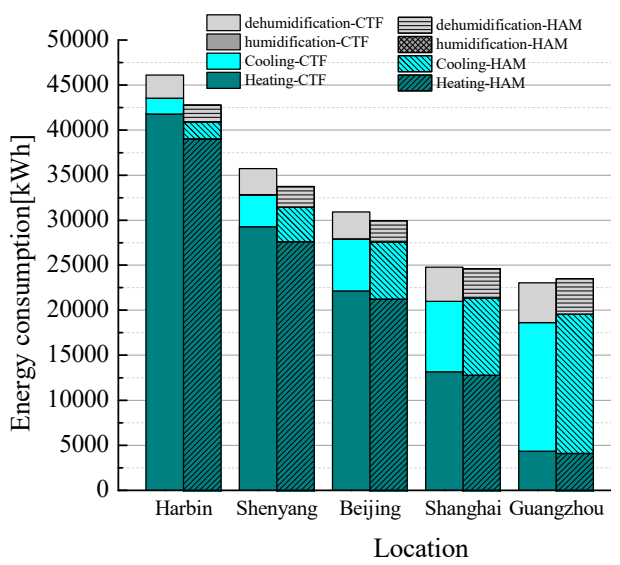

(a)

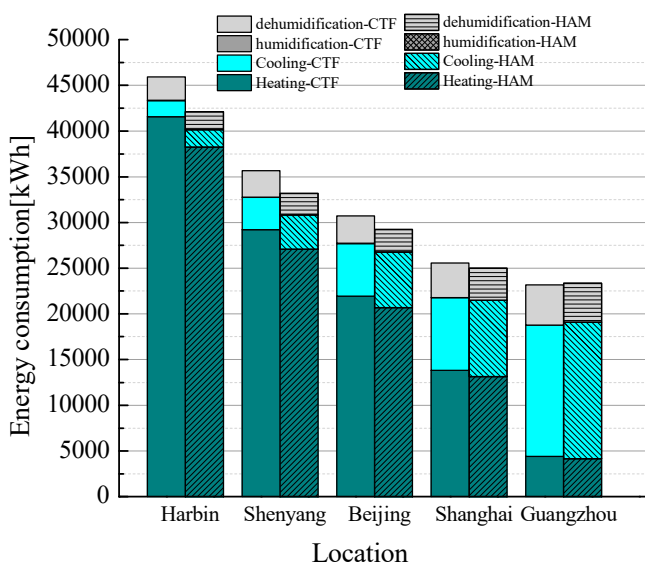

(b)

Figure 9. Different parts of energy consumption in the official building in different area: (a) EPS; (b) rock wool.

It can be seen from Figure 9 that the total energy consumption of Harbin, Shenyang, Beijing, Shanghai, and Guangzhou is reduced in turn. Additionally, the latent heat energy consumption of air conditioning is smaller than that dealing with heating and cooling. The energy used to adjust the temperature of the room is greater than the energy used to adjust the humidity in the room.

\subsubsection{Additional Factor of Coupled Heat and Moisture}

As mentioned above, the calculation process, compared to the traditional calculation method, is particularly complex due to needing to refer to many hygrothermal properties of materials; hence, it is difficult to popularize in engineering and practical applications in the short term. Therefore, the building energy consumption can be corrected by the additional coefficient method. Based on the additional factor of the traditional method, the energy consumption can become more accurate. That is to say, the value of the energy consumption can be achieved by multiplying the basic algorithm with the additional coefficient. Figure 10 shows the additional coefficient of building energy consumption in different regions.

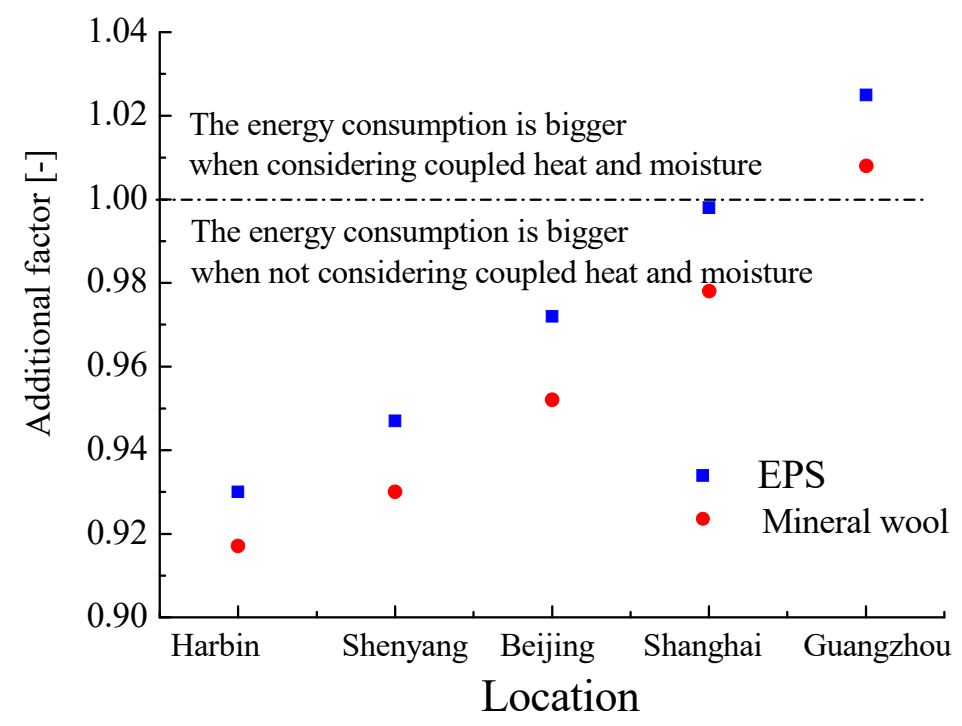

Figure 10. The correction factor of total energy consumption in official buildings in different areas. 


\section{Conclusions}

This paper measured the dynamic hygrothermal properties of five kinds of building materials. The measured properties were introduced into the energy software WUFI-Plus to imitate the effect of moisture migration, accumulation, and dynamic thermal processes on the calculation of building energy consumption and the evaluation of indoor staff comfort. The research contributes to the more rational use of envelope heat and moisture transfer in buildings, in order to achieve the purpose of reducing building energy consumption and improving indoor comfort. The main conclusions are as follows:

- Due to the moisture absorption and desorption performance of the building envelope, the distribution of indoor temperature and humidity state points is narrow when considering the coupled heat and moisture in the wall. If the heat and moisture transfer in the wall is taken into account, the difference between the average surface temperature and the indoor air temperature is 0.13 degrees or so less than when not taking this into account;

- The heating and cooling energy consumption that considers the coupled heat and moisture transfer is less than that which does not. The moisture absorption and desorption capacity of the envelope has a significant effect on the indoor relative humidity fluctuation. The latent energy consumption is calculated by the HAM method, which is smaller than the one obtained by the conventional algorithm;

- With the location of the building changing from north to south, the coupling effect of heat and moisture on the annual energy consumption of buildings varies from positive to negative. For the EPS thermal insulation system, the effect ratio of heat and moisture coupling varies from $6.97 \%$ to $-2.49 \%$. For the mineral wool insulation system, the effect ratio varies from $8.3 \%$ to $-0.84 \%$;

- The utilization of an additional coefficient of coupled heat and moisture can be used to correct the deviation of traditional calculation of building energy consumption without considering the heat and moisture coupling.

The research findings of this paper fill the blank that coupled heat and moisture transfer is ignored in thermal analysis, and energy consumption and comfort analysis. It is helpful in making use of the heat and moisture transfer of the building envelope more reasonably, in order to achieve the purpose of reducing building energy consumption and improving indoor comfort.

Author Contributions: Conceptualization, S.Y. and Y.C.; methodology, Y.C.; software, Y.C.; validation, Y.C.; formal analysis, Y.C.; Writing-Original Draft preparation, Y.C.; Writing-Review and Editing, Y.C.; manuscript revising, Y.C., F.H. and Y.S.; project administration, S.Y.; funding acquisition, S.Y.

Funding: This research was funded by National Key R\&D Program of China, grant number 2017YFC0702601; the National Natural Science Funds, grant number 51308353, the Opening Funds of State Key Laboratory of Building Safety, Built Environment, grant number BSBE2016-06; the Shenyang Young and Middle-aged Science and Technology Innovation Talents Program, grant number RC170313 and the Liaoning Provincial Natural Foundation, grant number 20170540761.

Conflicts of Interest: The authors declare no conflict of interest.

\section{References}

1. Laborel-Préneron, A.; Aubert, J.E.; Magniont, C.; Tribout, C.; Bertron, A. Plant aggregates and fibers in earth construction materials: A review. Constr. Build. Mater. 2016, 111, 719-734. [CrossRef]

2. Feng, C.; Yu, X.; Wang, D. Measurements on the Hygric Properties of Autoclaved Aerated Concrete. J. Civ. Archit. Environ. Eng. 2016, 38, 125-131. (In Chinese)

3. Yu, S.; Cui, Y.; Feng, C.; Sun, L. Systematic Errors in Steady-state Measurements on the Thermal Conductivities of Insulation Materials. Bulid. Sci. 2016, 32, 50-54. (In Chinese)

4. Park, B.; Srubar, W.V.; Krarti, M. Energy performance analysis of variable thermal resistance envelopes in residential buildings. Energy Build. 2015, 103, 317-325. [CrossRef] 
5. Clark, W.W. Variable Thermal Insulation. Available online: http://www.pss-system.gov.cn/sipopublicsearch/ patentsearch/showViewList-jumpToView.shtml (accessed on 4 April 2013).

6. Menyhart, K.; Krarti, M. Potential energy savings from deployment of Dynamic Insulation Materials for US residential buildings. Build. Environ. 2017, 114, 203-218. [CrossRef]

7. Karagiozis, A.; Künzel, H.; Holm, A. WUFI Ornl-ibp A North American Hygrothermal Model; Fraunhofer Institute of Building Physics: Munich, Germany, 2014.

8. Vesper, S.; Barnes, C.; Ciaccio, C.E.; Johanns, A.; Kennedy, K.; Murphy, J.S.; Nunez-Alvarez, A.; Sandel, M.T.; Cox, D.; Dewalt, G.; et al. Higher Environmental Relative Moldiness Index (ERMI) values measured in homes of asthmatic children in Boston, Kansas City, and San Diego. J. Asthma 2013, 50, 155-161. [CrossRef] [PubMed]

9. D.O. Energy. Energyplus V8.9.0 Engineering Reference; U.S. Department of Energy: Washington, DC, USA, 2018.

10. Chen, Z. Research of Vegetation System's Effects on Outdoor Thermal Environment of Residential Communities in Hot-Humid Climate; School of Architecture, South China University of Technology: Guangzhou, China, 2010. (In Chinese)

11. Chang, R.; Zhang, Q.; Asano, K. Study on Typical Weather Year Data of Main Cities in China. China Constr. Heat. Refrig. 2002, 4, 50-52. (In Chinese)

12. Jin, L.; Zhang, Y.; Zhang, Z. Influences of high temperature and humidity on thermal and humid responses of people in hot-humid areas. Heat. Vent. Air Cond. 2016, 46, 122-127. (In Chinese)

13. Wang, Y.; Liu, Y.; Wang, D.; Liu, J. The correction coefficients for the building air-conditioning load accounting for the whole building hygrothermal transfer process for major cities in China. Indoor Built Environ. 2016, 26, 642-661. [CrossRef]

14. You, S.; Li, W.; Ye, T.; Hu, F.; Zheng, W. Study on moisture condensation on the interior surface of buildings in high humidity climate. Build. Environ. 2017, 125, 39-48. [CrossRef]

15. Cheng, A.; Hsin, Y.; Lin, W.-T. Effects of mold growth on building materials by different environments in Taiwan. KSCE J. Civ. Eng. 2014, 18, 1083-1090. [CrossRef]

16. Rupp, R.F.; Vásquez, N.G.; Lamberts, R. A review of human thermal comfort in the built environment. Energy Build. 2015, 105, 178-205. [CrossRef]

17. Thomsen, K.E.; Rose, J.; Mørck, O.; Jensen, S.Ø.; Østergaard, I.; Knudsen, H.N.; Bergsøe, N.C. Buildings. Energy consumption and indoor climate in a residential building before and after comprehensive energy retrofitting. Energy Build. 2016, 123, 8-16. [CrossRef]

18. Lucchi, E.; Tabak, M.; Troi, A. The "Cost Optimality" Approach for the Internal Insulation of Historic Buildings. Energy Procedia 2017, 133, 412-423. [CrossRef]

19. M.Kunzel, H. Simultaneous Heat and Moisture Transport in Building Components; Fraunhofer Institute of Building Physics: Munich, Germany, 1995.

20. Abdou, A.; Budaiwi, I. The variation of thermal conductivity of fibrous insulation materials under different levels of moisture content. Constr. Build. Mater. 2013, 43, 533-544. [CrossRef]

21. Taoukil, D.; El bouardi, A.; Sick, F.; Mimet, A.; Ezbakhe, H.; Ajzoul, T. Moisture content influence on the thermal conductivity and diffusivity of wood-concrete composite. Constr. Build. Mater. 2013, 48, 104-115. [CrossRef]

22. Feng, C.; Janssen, H.; Feng, Y.; Meng, Q. Hygric properties of porous building materials: Analysis of measurement repeatability and reproducibility. Build. Environ. 2015, 85, 160-172. [CrossRef]

(C) 2019 by the authors. Licensee MDPI, Basel, Switzerland. This article is an open access article distributed under the terms and conditions of the Creative Commons Attribution (CC BY) license (http://creativecommons.org/licenses/by/4.0/). 